\title{
Polymodal Sensory Thalamic Inputs to the Rat Lateral Amygdala are Facilitated by Chronic Ethanol Exposure and Regulate Withdrawal- associated Anxiety
}

\author{
Melissa Morales ${ }^{1,2}$, Molly M. McGinnis ${ }^{1}$, Ann M. Chappell ${ }^{1}$, Brian C. Parrish ${ }^{1}$, and Brian A. \\ $\mathrm{McCool}^{1}$ \\ ${ }^{1}$ Dept. Physiology \& Pharmacology, Wake Forest School of Medicine, Winston-Salem NC \\ ${ }^{2}$ Current Address: College of Pharmacy, Binghamton University, Binghamton NY
}

Author Contributions: MM and BAM designed research; MM, MMM, AEC, BPP, and BAM performed experiments; MM, MMM, and BAM analyzed data; MM and BAM wrote the manuscript

Correspondence:

Brian A. McCool, Ph.D.

Dept. Physiology \& Pharmacology

Wake Forest School of Medicine

Winston-Salem, North Carolina, 27157

United States

bmccool@wakehealth.edu

336-716-8608

Acknowledgements: This work was supported by the following grants from the National Institutes of Health/National Institute on Alcohol Abuse and Alcoholism - R01 AA014445 (BAM), R01 AA023999, P50 AA026116 (BAM), R21 AA026572 (BAM), T32 AA007565 (MM, MMM), F32 AA024949 (MM), and F31 AA025514 (MMM) 


\section{Abstract}

Thalamic projections to the lateral amygdala regulate the acquisition of conditioned aversive and reward-related behaviors. Recent work suggests that exposure to chronic ethanol up-regulates presynaptic function of lateral amygdala stria terminalis inputs which contain projections from somatosensory thalamic nuclei. To understand potential contributions by thalamic inputs and their role in the expression of withdrawal-associated aversive behaviors, we integrated optogenetic and chemogenetic approaches with in vitro measures of synaptic function and anxiety-like behavior. We found that expression of Channelrhodopsin in the caudal extension of the posterior thalamic group (cPO) produced monosynaptic glutamatergic synaptic responses in lateral amygdala principal neurons that could be inhibited by co-expression of the hM4-GiDREADD. Chronic ethanol exposure increased glutamate release from these cPO terminals but did not impact inhibition by the DREADD agonist, CNO. Systemic injection of CNO specifically reduced withdrawal-related increases in anxiety-like behaviors in animals expressing the Gi-DREADD in cPO. And, microinjection of CNO directly into the lateral amygdala mimicked this anti-anxiety effect. These findings suggest that the cPO-LA circuit is vulnerable to chronic ethanol exposure and plays an important role in regulating anxiety-like behavior following chronic ethanol exposure. 


\section{Introduction}

Alcohol use disorder (AUD) is characterized by excessive alcohol intake and a negative emotional state when alcohol is not in use. As AUD and anxiety are strongly connected and anxiety following cessation of drinking is a strong contributor to relapse, animal models are necessary to understand not only the behavioral/functional consequences of alcohol withdrawal, but also the neurophysiological and circuitry that are involved. For instance, chronic ethanol exposure via vapor inhalation induces anxiety-like behavior and increases ethanol consumption during withdrawal—two hallmarks of ethanol dependence (reviewed in (Koob, 2003; Koob, 2013)). In addition, ethanol dependence produces neurophysiological changes in several key brain regions associated with the fear/anxiety circuit, including the lateral/basolateral amygdala (McCool, 2011; McCool et al., 2010).

The basolateral amygdala is a highly conserved structure made up predominantly of glutamatergic principal neurons and a smaller proportion of GABAergic interneurons (McDonald, 1982; McDonald, 1985; McDonald, 1992). The interactions between and activity of these neuronal populations regulate the expression of anxiety-like and fear-related behaviors (Siuda et al., 2016). The basolateral amygdala consists of the lateral amygdala (LA) and basal subdivisions. Located dorsally, the LA receives sensory information from the sensory cortex and thalamus and projects extensively to the basolateral amygdala as well as distant brain regions. These projections ultimately regulate physiological/psychological responses related to reward as well as conditioned and unconditioned aversive behaviors.

Chronic ethanol exposure produces robust effects on both anxiety-like behavior and synaptic transmission onto basolateral amygdala principal neurons (Christian et al., 2013; Christian et al., 2012; Diaz et al., 2011b; Lack et al., 2007; Morales et al., 2018; Robinson et al., 
2016). Importantly, chronic intermittent ethanol (CIE) vapor exposure produces distinct, preand post-synaptic alterations in afferents that are both input- and exposure-duration (Morales et al., 2018). These works have shown that glutamatergic afferents arriving via the stria terminalis (ST; dorsal to the central amygdala) express a presynaptic form of 'ethanol plasticity’ and develop with shorter exposures compared to the postsynaptic potentiation expressed at external capsule (EC) regardless of age or sex. This suggests that the initial presynaptic facilitation of ST inputs may be critical for the development of behavioral and synaptic withdrawal symptomology. These CIE/withdrawal data parallel fear-conditioning studies that demonstrate time-dependent activation of the ST and then the EC causes use-dependent, associative postsynaptic plasticity at the cortical/lateral inputs onto basolateral amygdala neurons (Cho et al., 2012; Humeau et al., 2003). The interaction between medial presynaptic glutamate release and lateral postsynaptic potentiation may reflect a crucial mechanism for modulating fear- and ethanol-conditioned behaviors.

Research on the circuitry controlling fear and anxiety responses has recently focused on interactions between the BLA and prefrontal cortex. However, early work in this field demonstrated a critical role for thalamic structures. For example, the LA receives sensory information from several thalamic subdivisions. Notably, the caudal extension of the posterior thalamic group (cPO) - which includes the intralaminar nucleus (PIN), the triangular cell subdivision (PoT), the medial subdivision of the medial geniculate (mMG), and the suprageniculate nucleus (Sg) - is a collection of polymodal sensory areas located just medial to the medial geniculate nucleus (MG) and lateral to the anterior pretectal (APT) area. The cPO sends dense projections to the LA via the stria terminalis (Doron and Ledoux, 1999; LeDoux et al., 1990; Nitecka et al., 1979); and permanent lesions to the PIN, Sg, and mMG reduce 
elevations in c-fos immunoreactivity in the LA following exposure to foot-shocks (Lanuza et al., 2008). These studies highlight the importance of cPO inputs to the LA for fear-related behaviors; however, their precise interactions during alcohol withdrawal are unknown. Therefore, the current study utilized chemo- and optogenetic approaches with behavioral and electrophysiological methods to determine the role of cPO inputs into the LA in mediating anxiety-like behavior following ethanol withdrawal. We show that these cPO inputs are both sensitive to chronic ethanol exposure and are important modulators of withdrawal-associated anxiety.

\section{Methods}

\section{Animals}

Upon arrival, four to five-week old male Sprague-Dawley rats (Envigo; Indianapolis, IN) were pair-housed and maintained on a reverse 12:12 h light dark cycle (lights on at 9PM). Rats were given unlimited access to standard rat chow and water throughout the experimental procedures. All animal care procedures were in accordance with the NIH Guide for the Care and Use of Laboratory Animals in accordance with the Society for Neuroscience Policies on the Use of Animals and Humans in Neuroscience Research and approved by the Wake Forest School of Medicine Animal Care and Use Committee.

\section{Surgical procedures}

Rats were anesthetized with isoflurane (2.5-5\% for induction and maintenance) and underwent aseptic surgery using a stereotaxic apparatus (Neurostar, Germany). Bilateral injections of AAV vectors (rAAV5/CamKII-hChR2(H134R)-eYFP-WPRE and rAAV8/hSyn-hM4D-mcherry; coinjected at 1:1 ratio; both from UNC vector core) were administered using a Harvard Apparatus (Holliston, MA) pump at a rate of $0.1 \mu \mathrm{l} / \mathrm{min}$, for a total volume of $1 \mu \mathrm{l}$ per side (cPO injection 
coordinates: -5.76 anterior/posterior; \pm 3.00 medial/lateral; and, -6.20 dorsal/ventral). We removed sutures 1 week later and pair-housed the animals. For electrophysiology studies and systemic clozapine-N-oxide injections, viral expression progressed for four weeks prior to the chronic intermittent ethanol vapor inhalation (below).

For the behavioral studies using BLA microinjections, rats underwent a second surgery two weeks after microinjection of the viral constructs to implant chronic guide cannulae (Plastics One; Roanoke, VA). We placed cannulae bilaterally into the BLA (BLA coordinates: -2.80 anterior/posterior; \pm 5.00 medial/lateral; and, -7.58 dorsal/ventral) and affixed them to the skull with dental cement according to previous publications (Diaz et al., 2011a; McCool and Chappell, 2007; McCool et al., 2014). To retain the patency of the guide cannulae, we placed sterile obturators into each cannulae and replaced them as necessary. Rats were pair-housed 3 days following this second surgery. One week prior to the CIE exposure, we microinjected all rats with $0.5 \mu \mathrm{l} /$ side aCSF to habituate them to the procedural manipulations.

\section{Chronic intermittent ethanol (CIE) vapor exposure}

Chronic intermittent ethanol (CIE) vapor exposure lasted for 7 days using standard procedures (Christian et al., 2012; Lack et al., 2007; Morales et al., 2018; Robinson and McCool, 2015). Briefly, we placed pair-housed rats in their home cages into a larger, custom-built Plexiglas chamber (Triad Plastics, Winston-Salem, NC). At the onset of the light cycle (9pm EST), we applied ethanol vapor (15-20 mg/L) for $12 \mathrm{~h}$ each day into the exposure chambers. We housed ethanol-naïve control animals under identical conditions except that they received roomair only while in the chambers. This 7 day exposure is sufficient to increase glutamate release from stria terminalis inputs to the BLA using electrical stimulation (Christian et al., 2013; Morales et al., 2018). Body weights were collected daily; and, tail blood samples were collected 
during the CIE exposure to monitor blood ethanol concentrations and adjust ethanol vapor levels as necessary. Blood samples were collected from any individual animal only once during the exposure; and blood ethanol concentrations were determined from plasma using a commercially available alcohol dehydrogenase/NADH enzymatic assay (Diagnostic Chemicals Limited, Oxford CT). The average BEC during the CIE vapor exposure was $219.15 \pm 12.65 \mathrm{mg} / \mathrm{dl}$.

\section{Whole-cell Patch Clamp Electrophysiology}

Slice preparation. Rats were anesthetized with isoflurane and decapitated. Brains were immediately removed and incubated for 5 minutes in an ice-cold sucrose-modified artificial cerebral spinal fluid (aCSF) solution containing (in mM): 180 Sucrose, $30 \mathrm{NaCl}, 4.5 \mathrm{KCl}, 1$ $\mathrm{MgCl}_{2} \cdot 6 \mathrm{H}_{2} \mathrm{O}, 26 \mathrm{NaHCO}_{3}, 1.2 \mathrm{NaH}_{2} \mathrm{PO}_{4}, 10$ glucose, 0.10 ketamine. Coronal amygdala slices (400 $\mathrm{MM}$ ) were prepared using a VT1200/S vibrating blade microtome (Leica, Buffalo Grove, IL) and incubated for $\geq 1 \mathrm{~h}$ in a room temperature, oxygenated, standard aCSF solution containing (in mM): $126 \mathrm{NaCl}, 3 \mathrm{KCl}, 1.25 \mathrm{NaH}_{2} \mathrm{PO}_{4}, 2 \mathrm{MgSO}_{4}, 26 \mathrm{NaHCO}_{3}, 10$ glucose, and $2 \mathrm{CaCl}_{2}$ prior to recordings. All chemicals were from Sigma-Aldrich (St. Louis, MO) or Tocris (Ellisville, Missouri).

Whole-cell patch-clamp recording. We performed whole-cell recordings from lateral amygdala neurons within coronal brain slices according to established procedures (Morales et al., 2018). In a submersion-type recording chamber, room temperature aCSF continuously perfused brain slices at a rate of $2 \mathrm{ml} / \mathrm{min}$. We pharmacologically isolated glutamatergic responses with the $\mathrm{GABA}_{\mathrm{A}}$ antagonist, picrotoxin $(100 \mu \mathrm{M}$ in the bath aCSF). The intracellular recording solution for synaptic responses contained (in mM): $145 \mathrm{CsOH}, 10$ EGTA, 5 NaCl, 1 MgCl, 10 HEPES, 0.4 QX314, $1 \mathrm{CaCl}_{2}$, 4 Mg-ATP, 0.4 Na-GTP (pH 7.25, modified with gluconic acid, osmolarity between 285-295 mmol/kg, modified with sucrose). For current-clamp recordings, 
K-gluconate replaced Cs-gluconate in this solution. We collected cellular/synaptic responses using an Axopatch 700B amplifier (Molecular Devices, Foster City, CA) and later analyzed the responses off-line using pClamp software (Molecular Devices, Foster City, CA). The electrophysiological characteristics of lateral amygdala principal neurons - high membrane capacitance $(>100 \mathrm{pF})$ and low access resistance ( $\leq 25 \mathrm{M} \Omega$ ) (Rainnie et al., 1993; Washburn and Moises, 1992) - were used as inclusion criteria for analysis. Changes of $>20 \%$ for whole-call capacitance or access resistance at any point during the duration of the recording excluded cells from analysis.

Optogenetics \& Chemogenetics. To measure light-evoked action potentials or glutamate release (ChR2-mediated) from cPo terminals in the lateral amygdala, we placed a naked fiber optic cable (400 $\mu$ m diameter) immediately above the tissue (directly over the injection site or stria terminalis) and delivered brief light stimulations from a 473nm laser triggered by 5V TTL stimulations controlled from the acquisition software. The 473nm light durations varied from $2 \mathrm{msec}$ to $45 \mathrm{msec}$ in the cPO recordings; and, we used a $5 \mathrm{msec}$ stimulus delivered at $0.5 \mathrm{~Hz}$ for the synaptic responses in the lateral amygdala. We assessed glutamate release probability with two light-evoked responses separated by a 50msec inter-stimulus interval and derived a pairedpulse ratio (PPR) from light-evoked EPSC amplitudes using a conservative estimate ([Peak 2 amplitude - Peak 1 amplitude] / Peak 1 amplitude; (Christian et al., 2013; Diaz et al., 2011b; Lack et al., 2007; Morales et al., 2018)). Gi DREADD modulation of synaptic responses was measured by acute application of the DREADD agonist, cloxapine-N-oxide (CNO, 10 $\mu \mathrm{M})$. Following a 5min baseline period, we perfused CNO onto slices for $10 \mathrm{~min}$, followed by a 10 min washout period. We applied CNO to brain slices only once; CNO-inhibition only partially recovered after extensive washing. 


\section{Elevated Plus Maze}

We used previously standardized procedures to assess anxiety-like behavior during withdrawal using the Elevated Plus Maze (EPM, 5min test; (Diaz et al., 2011a; Morales et al., 2015; Morales et al., 2018)). For the systemic injection studies, we injected rats with CNO (5 mg/kg i.p.) or saline (1 ml/kg i.p) 30 min prior to placement onto the central junction of the EPM facing an open arm. For the intracerebral studies, we microinjected rats, via an injection needle which extended $1.0 \mathrm{~mm}$ past the guide cannula, with CNO $(300 \mu \mathrm{M})$ or aCSF (both at $0.5 \mu \mathrm{l} /$ side over 1min) 5min prior to placement onto the EPM . Animals with unilateral or no expression of the Gi DREADD construct in cPO or BLA terminal fields were excluded from the analysis. Open arms were dimly lit ( 40 lux). The time spent in each arm and the number of arm entries represented anxiety-like behavior and general locomotion, respectively. A computer equipped with MED-PC (Med Associates) connected to the plus maze collected beam breaks; and EPM test sessions were also videotaped (Panasonic Model \#P0H1000, Rockville, MD) to generate heat maps of the centroid for each animal using EthoVision XT (Version 11.5, Noldus Technology, Leesburg, VA). The apparatus was cleaned with warm water/mild soap and thoroughly dried between animals.

\section{Statistics}

All data analyses were conducted using GraphPad Prism 8.0 (GraphPad Software Inc., La Jolla, CA). Data were analyzed via t-tests or analysis of variance (ANOVA), with Bonferroni post-hoc tests used to determine the locus of effect, where appropriate. Significance was set at $\mathrm{p}<0.05$. Data are presented as mean \pm SEM throughout the text and figures.

\section{Results}


Withdrawal increases release probability at cPO inputs onto LA neurons but does not alter chemogenetic inhibition

To confirm that cPO terminals in the BLA could regulate neurophysiological changes that emerge during ethanol withdrawal, we co-injected Channelrhodopsin with the Gi-DREADD viral construct into the cPO. Expression of both the Channelrhodopsin and Gi-DREADD constructs produced intense fluorescence within the cPO (mCherry fluorescence shown in Fig. $1 \mathrm{~A}_{1}$ ). Current-clamp recordings of a cPO neurons (Fig. $1 \mathrm{~B}_{1}$ ) revealed that light exposures of increasing durations produced depolarizations that reached threshold at durations $\geq 4 \mathrm{msec}$. Light-gated (45msec duration) currents measured in voltage-clamp in the presence of picrotoxin (see Methods) were insensitive to bath application of the glutamate ionotropic antagonists DNQX $(20 \mu \mathrm{M})$ and APV $(50 \mu \mathrm{M}$; Fig 1B 2$)$.

Expression of Channelrhodopsin/Gi-DREADD also produced intense fluorescence along the stria terminalis (dorsal to the central amygdala, CeA) and within the lateral nucleus of the amygdala (LA, Fig. 1A2). These findings confirm previous publications with traditional retrograde tracers showing that the $\mathrm{cPO}$ sends strong projections to the lateral/basolateral amygdala (Doron and Ledoux, 1999; Doron and Ledoux, 2000; Lanuza et al., 2008). However, these cPO inputs appear to be largely localized in the lateral amygdala. Indeed, expression of Channelrhodopsin in cPO terminals produced light-gated synaptic responses recorded from lateral amygdala neurons that were inhibited by DNQX/APV (Fig. 1C 1 ). Importantly, TTX $(1 \mu \mathrm{M})$ completely inhibited these light-evoked synaptic responses; and, bath application of the voltage-gated potassium channel blocker, 4-AP (2mM), largely reversed the inhibition by TTX (Fig. $1 \mathrm{C}_{2}$ ). Together, these data suggest that $\mathrm{cPO}$ neurons send monosynaptic glutamatergic projections to lateral amygdala principal neurons. 
Previous work using electrical stimulation has shown that chronic ethanol exposure can increase presynaptic function of stria terminalis inputs onto lateral and basolateral amygdala neurons (Christian et al., 2013; Morales et al., 2018). We utilized a similar paired-pulse protocol that instead elicited light-evoked responses with an inter-stimulus duration of 50msec to measure the effects of chronic ethanol exposure specifically on cPO terminals onto LA neurons. We found here that CIE exposure also increases glutamatergic release probability from cPO terminals onto lateral amygdala neurons. Neurons from air-exposed controls $(n=7)$ expressed paired-pulse ratios of $-0.16 \pm 0.03$ while those from CIE/24h withdrawal animals $(n=10)$ had a ratio of $-0.41 \pm 0.03(\mathrm{p}<0.05$, t-test; Fig. $2 \mathrm{~A})$. Like findings with electrical stimulation of the stria terminalis (Christian et al., 2013; Morales et al., 2018), these data show that CIE/withdrawal increases glutamate release from cPO inputs onto LA neurons.

To understand the behavioral role of CIE-dependent alterations in glutamate release from cPO terminals in the LA, we examined Gi-DREADD modulation of light-evoked responses from these cPO-LA terminals from either air controls or CIE-exposed animals $24 \mathrm{~h}$ after the last exposure (Fig. 2B 1$)$. Bath application of CNO $(10 \mu \mathrm{M})$ decreased glutamate release from cPO terminals from both treatment groups to a similar extent (Fig. $\left.2 \mathrm{~B}_{2}\right)$. CNO inhibition was 27.4 $\pm 9.9 \%$ in air-exposed neurons $(n=5)$ and $30.4 \pm 3.3 \%$ in CIE/24h withdrawal neurons ( $\mathrm{n}=6$; $\mathrm{p}>0.05$, t-test). CNO inhibition did not appear to reverse even after extensive wash out (10min).

\section{Systemic Injection of CNO Reverses Withdrawal-associated Anxiety-like Behavior}

To understand the potential role of cPO in the expression of anxiety-like behavior following chronic ethanol exposure, we expressed the Gi DREADD in cPO neurons, exposed them to CIE, and measured the effects of systemically administered saline or CNO (5mg/kg, I.P.) 24h after the last ethanol exposure on the elevated plus maze (Figure 3A). Two-way ANOVA of 
open arm time (Figure $3 \mathrm{~B}_{1}$ ) revealed a significant main effect of CNO treatment $(\mathrm{p}<0.05, \mathrm{~F}[1$, 24]=6.697); and, withdrawal animals injected with CNO spent significantly more time in the open arm compared to their saline counterparts ( $\mathrm{p}<0.05$, Bonferroni’s multiple comparisons posttest). For open arm entries, the two-way ANOVA showed significant main-effects of both WD $(\mathrm{F}[1,24]=4.84, \mathrm{p}<0.05)$ and $\mathrm{CNO}(\mathrm{F}[1,24]=5.45, \mathrm{p}<0.05)$ but no interaction $(\mathrm{F}[1,24]=3.04$, $\mathrm{p}>0.05)$. Air+CNO animals made significantly more open arm entries than the Air+Saline group ( $<<0.05$, Bonferroni’s multiple comparison post-test); but open arm entries was not significantly altered by CNO in the WD group ( $>0.05)$. There were no significant interactions $(F[1,24]=0.2 .459, \mathrm{p}>0.05)$ or main effect of $\mathrm{CNO}(\mathrm{F}[1,25]=2.768, \mathrm{p}>0.05)$ between treatment groups for total arm entries (Figure $3 \mathrm{~B}_{2}$ ) or closed arm entries (interaction $-\mathrm{F}[1,25]=0.001$, $\mathrm{p}>0.05, \mathrm{WD}-\mathrm{F}[1,25]=1.19, \mathrm{p}>0.05, \mathrm{CNO}-\mathrm{F}[1,25]=0.01, \mathrm{p}>0.05)$. There was a significant main effect of WD on total arm entries $(F[1,25]=7.579, \mathrm{p}<0.05)$ that appears to be driven by the impact of WD on open arm entries. These data all suggest that there was no substantial locomotor effects of the chronic ethanol exposure or the CNO.

To confirm that the observed CNO effects were specific to cPO neurons expressing the DREADD receptor, a separate group of rats underwent surgery but were only injected with Channelrhodopsin. Using the same experimental design, rats from air- or CIE-treatments were injected with either saline or CNO (5 mg/kg, I.P.) 30min prior to measurement on the elevated plus maze. The two-way ANOVA of the data from these "no DREADD” controls showed a significant main effect of WD on open-arm time (Figure $3 C_{1} ; F[1,13]=8.37, p<0.05$ ) compared to the Air controls but no interaction $(F[1,13]=1.459, \mathrm{p}>0.05)$ and no main effect of $\mathrm{CNO}$ $(F[1,13]=0.02, p>0.05)$. Unlike the DREADD-expressing animals, open arm entries were not significantly different for either the WD $(\mathrm{F}[1,13]=3.186, \mathrm{p}>0.05)$ or CNO factors $(\mathrm{F}[1,13]=0.71$, 
$\mathrm{p}>0.05)$; and there was no interaction between factors $(\mathrm{F}[1,13]=1.18, \mathrm{p}>0.05)$. There was again no significant interactions between the ethanol exposure and CNO injection $(F[1,13]=0.471$, $\mathrm{p}>0.05)$ and main effects of $\mathrm{WD}(\mathrm{F}[1,13]=1.125, \mathrm{p}>0.05)$ or $\mathrm{CNO}(\mathrm{F}[1,13]=0.003, \mathrm{p}>0.05)$ on total arm entries (Figure $3 \mathrm{C}_{2}$ ) or closed arm entries (interaction $-\mathrm{F}[1,13]=0.02$, $\mathrm{p}>0.05$; WD $\mathrm{F}[1,13]=0.09, \mathrm{p}>0.05 ; \mathrm{CNO}-\mathrm{F}[1,13]=0.581, \mathrm{p}>0.05)$.

Gi DREADD inhibition of cPO terminals in the Lateral Amygdala Attenuates Withdrawalinduced Anxiety-like Behavior

Results from our systemic CNO injections strongly suggest a role for the $\mathrm{cPO}$ in modulating anxiety-like behavior following ethanol withdrawal. We directly examined the contributions of cPO terminals in the lateral amygdala by expressing the hM4D Gi-DREADD in cPO, microinjecting the agonist CNO into the LA to inhibit glutamate release from these terminals, and measuring anxiety-like behavior on the elevated plus maze following air or CIE exposure (Fig. 4A \& B). For open arm time (Fig. 4C 1 ), there was a significant interaction $(\mathrm{F}[1,22]=4.88, \mathrm{p}<0.05)$ between treatment (Air vs. CIE/WD) and microinjection (Vehicle vs. CNO) groups. Post-test analysis showed that this was due to a significant increase in open arm time following CNO microinjection in the CIE/WD group $(\mathrm{p}<0.05$, Bonferroni’s multiple comparisons test) but not the Air group. There were no significant effects of either CIE/WD or CNO microinjection for the closed arm time, junction time, or open arm entry variables ( $\mathrm{p}>0.05$, two-way ANOVA). Total arm entries (Fig. 4C 2 ), a measure of locomotor activity in the plus maze, were significantly less in the CIE-treated groups (main effect, $F[1,22]=8.771, p<0.01$ ) but there was no main effect of CNO microinjection $(F[1,22]=0.01, p>0.05)$ and no interaction between CIE treatment and CNO microinjection $(F[1,22]=0.60, \mathrm{p}>0.05)$. Thus, while CIE had an effect on locomotor behavior in this experiment, CNO microinjection did not. This contrasts 
with the significant effect of CNO microinjection on open arm time in the CIE-treated animals but not air controls.

Like the systemic studies, we also examined the effects of CNO microinjection into the LA following air $(n=4)$ or CIE treatment $(n=5)$ in animals expressing 'empty' (no DREADD) vector in cPO terminals in a separate group of animals. Direct comparisons with the air and CIE groups from the previous experiment revealed that CNO had no effect on open arm time when the Gi DREADD was absent from cPO terminals (Fig. 4D 1 \& $\mathrm{D}_{2}$ ). Separate analysis of the air exposed animals showed no significant differences between the DREADD+Veh, DREADD+CNO, and No DREADD+CNO groups $(F[2,11]=0.60, \mathrm{p}>0.05)$. In the CIE-treated group, there was a significant difference between injection groups $(F[2,18]=6.453, p<0.01)$; and, CNO microinjection significantly increased open arm time in the DREADD+CNO animals relative to both the DREADD+Veh ( $<<0.05$, Bonferroni's multiple comparisons test) and No DREADD + CNO $(\mathrm{p}<0.01)$ rats. There were no significant differences between the DREADD+Veh, DREADD+CNO, and No DREADD+CNO microinjections for closed arm time (Air $-\mathrm{F}[2,11]=0.816, \mathrm{p}>0.05$; CIE $-\mathrm{F}[2,18]=0.327, \mathrm{p}>0.05$ ) or for total arm entries (Air $F[2,11]=0.762, p>0.05 ; \mathrm{CIE}-\mathrm{F}[2,18]=3.195, \mathrm{p}>0.05)$. These findings together suggest that the increased open arm time caused by microinjection of CNO requires DREADD expression on cPO terminals in the LA.

\section{Discussion}

In the current work we showed that microinjection of Channelrhodopsin into the cPO neurons labels terminal fields in the lateral amygdala and that these inputs are both glutamatergic and monosynaptic onto LA principal neurons. This is consistent with previous work showing that the posterior intralaminar and subgeniculate thalamic nuclei provide robust projections to the 
lateral amygdala (Doron and Ledoux, 1999; Gauriau and Bernard, 2004; Linke et al., 2000;

Smith et al., 2019), can drive local field potentials in an in vivo preparation (Doyere et al., 2003), and are glutamatergic (LeDoux and Farb, 1991). Withdrawal from chronic ethanol inhalation enhances light-evoked glutamate release probability from these synapses similar to previous findings with electrical stimulation showing that this ethanol exposure increases release from stria terminalis inputs to the lateral/basolateral amygdala (Christian et al., 2013; Morales et al., 2018). Co-expression of the hM4-Gi-DREADD in cPO terminals conferred inhibition by the DREADD agonist, CNO, that was not impacted by chronic ethanol at the concentration used here $(10 \mu \mathrm{M})$. Furthermore, systemic injection of CNO reduced anxiety-like behavior on the elevated plus maze in CIE-exposed rats, but not air-treated controls, when those animals expressed the Gi-DREADD in the cPO. Local activation of Gi DREADDS expressed on cPO terminals in the BLA using microinjection also attenuated withdrawal-anxiety. Finally, both the systemic effects of CNO and the effects of CNO microinjection were absent when GiDREADDs were not expressed indicating the effects of the agonist were DREADD-specific. Together, our findings suggest chronic ethanol/withdrawal facilitates the function of cPO terminals in the lateral amygdala and that this facilitation helps increase the expression of anxiety-like behaviors during withdrawal.

Our findings are consistent with previous literature showing that sub-regions within the cPO help regulate aversive behaviors by providing somatosensory input to the lateral amygdala. These behaviors can include unconditioned responses to itch/nociceptive (Gauriau and Bernard, 2004; Lipshetz et al., 2018), tactile (Gauriau and Bernard, 2004; Gonzalez-Hernandez et al., 2013), auditory (Bordi and LeDoux, 1994a; Bordi and LeDoux, 1994b), and visual stimuli (Eordegh et al., 2005). The cPO also regulates conditioned responses to somatosensory stimuli 
(Halverson et al., 2008; Romanski and LeDoux, 1992). Importantly, recent work using optogenetic approaches showed that cPO inputs to the lateral amygdala play a substantial role in the acquisition of these conditioned behaviors and that this process is blocked by local (LA) microinjection of ionotropic glutamate receptor antagonists (Kwon et al., 2014). These studies highlight the importance of cPO-LA circuitry in the expression of aversive behaviors.

Recent studies also suggest a strong relationship between the cPO-LA circuit and rewardrelated behaviors. For example, natural rewards like social play and food increase the expression of ‘neuronal activity’ markers like cFos (van Kerkhof et al., 2014) and phosphoMAP kinase (Nasser and McNally, 2013) in the lateral amygdala. Most notably, the acquisition of cuesucrose associations increased LA neuron firing in response to cue when measured with in vivo preparations and increased AMPA receptor synaptic function at stria terminalis inputs (but not external capsule); this increased postsynaptic function was positively correlated with task efficiency and accuracy (Tye et al., 2008). Similar findings for drug-related rewards like cocaine are also in the literature - from increased expression of markers for neuronal activity (Thomas and Everitt, 2001) to increased synaptic function at stria terminalis inputs to LA neurons (Goussakov et al., 2006). In a recent study, Rich and colleagues (Rich et al., 2019) examined the effects of cue-cocaine pairings, extinction, and reinstatement of LA neuron synaptic function. This study found bi-directional modulation of stria terminalis synapses onto LA associated with both learned cue-cocaine associations (facilitation) and extinction (depression). This study also utilized optogenetic approaches that expressed Channelrhodopsin around the medial geniculate (including most of the cPO) and found the same bidirectional shifts in light-gated EPSCs from these terminals recorded from LA neurons. These studies, together with the current work, 
highlight the important role of cPO-lateral amygdala circuits integrating somatosensory information with emotionally relevant behaviors.

Finally, it is worth noting that the non-contingent ethanol exposure used in the current work produces presynaptic facilitation of glutamate release at cPO inputs to the LA. The presynaptic facilitation described here using optogenetics is remarkably similar to previous work with electrical stimulation (Christian et al., 2013; Lack et al., 2009; Lack et al., 2007; Morales et al., 2018). In contrast, studies using contingent delivery of natural or drug rewards paired with cues have either suggested or directly demonstrated postsynaptic facilitation of synaptic function at these same inputs (Rich et al., 2019; Tye et al., 2008). Neither the Tye et al. study nor the Rich et al. study, which used both electrical stimulation of the stria terminalis as well as optogenetic activation of thalamic terminals, found any effects of the conditioning on presynaptic function of thalamic input pathways. Results from aversive-conditioning studies are more mixed with some showing that cue-aversion associations produce post-synaptic facilitation (Kim et al., 2007; Park et al., 2016) while others showing increased presynaptic function at stria terminalis inputs (Park et al., 2016; Shinnick-Gallagher et al., 2003). Interestingly, using auditory fear conditioning, Park and colleagues (Park et al., 2016) showed that the synaptic locus of facilitation (pre- versus post-) appears to depend upon the complexity of the tone used in the conditioning paradigm with 'less-complex' auditory stimuli producing greater presynaptic facilitation. The stria terminalis inputs thus appear to have the capacity to express both pre- and postsynaptic plasticity. This has been demonstrated directly using in vitro preparations. Shin et al. (Shin et al., 2010) showed that presynaptic 'plasticity' of stria inputs requires the activation of presynaptic kainite receptors expressed on these terminals. In contrast, pairing postsynaptic depolarization with activation of the same stria projections elicits postsynaptic facilitation that 
subsequently occludes any further changes in presynaptic function via the release of endogenous endocannabinoids and activation of presynaptic CB1 receptors expressed on these terminals. It is noteworthy then that the acquisition of conditioned behaviors is associated with increased firing of LA neurons in response to cue presentation (Tye et al., 2008). Regardless, it is not yet clear whether presynaptic facilitation by chronic ethanol at stria terminalis inputs is specific to ethanol or are related to either the contingency of drug delivery or the severity of intoxication during the exposure. But, recent work from our lab has shown that acute ethanol can directly inhibit presynaptic function of glutamate synapses during high frequency activity (Gioia et al., 2017; Gioia and McCool, 2017). This suggests that presynaptic facilitation following chronic ethanol exposure may represent a compensatory up-regulation in response to this acute suppression.

In conclusion, using optogenetic approaches, we have shown that withdrawal from chronic ethanol facilitates the presynaptic function of somatosensory thalamic inputs to lateral amygdala principal neurons. Subsequent down-regulation of these cPO terminals with chemogenetic approaches was sufficient to reduce the expression of withdrawal-related anxietylike behaviors. These data highlight the role of circuits integrating somatosensory perception with emotional behaviors following chronic ethanol exposure. Future experiments should explore the relationship of synaptic function and locus of adaptation along with contingent delivery of ethanol and severity of intoxication. 


\section{Figure Legends}

Figure 1. Expression of Channelrhodopsin in cPO produces monosynaptic glutamatergic responses in lateral amygdala principal neurons. (A) Immunofluorescence of mCherry expressed in the cPO injection site $\left(\mathrm{A}_{1}\right.$, left) and $\mathrm{cPO}$ projections along the stria terminalis dorsal to the central amygdala (CeA) that terminate in the lateral amygdala (LA, A2, right). MG: medial geniculate. BA: basolateral amygdala. (B) Recordings from cPO neurons showing that increasing light durations cause depolarizations that transition to action potentials at stimulations $>4 \mathrm{msec}\left(\mathrm{B}_{1}\right)$. Voltage-clamp recordings of light-gated whole-cell currents in cPO neurons were insensitive to the ionotropic glutamate receptor antagonists DNQX (AMPA receptor antagonist,

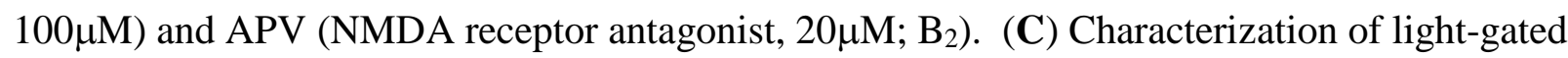
synaptic responses recorded from lateral amygdala principal neurons. Optical stimulation of cPO terminals (5msec light duration) evoked synaptic responses that were inhibited by the ionotropic glutamate receptor antagonists DNQX and APV $\left(\mathrm{C}_{1}\right)$. These responses were monosynaptic $\left(\mathrm{C}_{2}\right)$ as demonstrated by their complete inhibition by the voltage-gated sodium channel antagonist, tetrodotoxin (TTX, $1 \mu \mathrm{M}$; compare baseline/black trace with TTX/gray trace) and subsequent recovery with the addition of the voltage-gated potassium channel antagonist, 4AP (2mM, blue trace). For B \& C, the width of the bright blue lines above the traces represent the duration of light stimulation (50msec in $\mathrm{B}_{2}$; 5 msec in $\mathrm{C}$ ). Calibration bars in $\mathrm{B}_{2}$ and $\mathrm{C}_{1}: \mathrm{y}=$ 20pA, $x=40 \mathrm{msec}$.

Figure 2. Withdrawal from chronic intermittent ethanol (CIE/WD) increases glutamate release probability at cPO-LA inputs but does not disrupt hM4-Gi-DREADD modulation of cPO terminals and bath application of CNO $(10 \mu \mathrm{M})$ decreases glutamate release probability. 
Representative traces $\left(\mathrm{A}_{1}\right)$ from air-exposed control neurons (top, black trace) and CIE/WD neurons (bottom, red trace) were normalized to the amplitude of the first response to emphasize the relationships with the amplitude of the second response across treatment groups. Calibration bars: $x=50 m s e c ; y=20 p A$ for the Air trace, 50 pA for the CIE/WD trace. Summary of pairedpulse ratio data for exposure and CNO treatment groups $\left(A_{2}\right)$ shows a significant decrease in the ratio recorded from CIE/WD neurons ( $\mathrm{n}=7)$ relative to Air/control neurons $(\mathrm{n}=10)$. *** -$\mathrm{p}<0.001$, Student's t-test. (B) CIE/WD does not disrupt cPO terminal modulation by the GiDREADD agonist, CNO $(10 \mu \mathrm{M})$. Representative traces $\left(\mathrm{B}_{1}\right)$ illustrate the effects of CNO application in the two treatment groups. Response amplitudes have been normalized across treatment group to allow comparisons with the CNO (calibration bars: $\mathrm{x}=20 \mathrm{msec}, \mathrm{y}=20 \mathrm{pA}$ in Air neuron, 40pA in CIE/WD neuron). Summary of CNO inhibition across the treatment groups $\left(\mathrm{B}_{2}\right)$ shows no significant alterations in hM4-Gi-DREADD modulation by the CIE/WD treatment ('n.s.' = not significant).

Figure 3. Systemic activation of hM4-Gi-DREADD expressed in the cPO attenuates anxiety-like behavior expressed during withdrawal. (A) Representative heat maps demonstrating location/duration of time spent on the open and closed arms for each group (Air controls \pm CNO, $\mathrm{CIE} / \mathrm{WD} \pm \mathrm{CNO}$ ). Calibration bar (right) indicates color code for time duration in each location. (B) Intraperitoneal injection of CNO (5 mg/kg) significantly increased open arm time $\left(\mathrm{B}_{1}\right)$ relative to saline $(1 \mathrm{ml} / \mathrm{kg})$ in CIE/WD animals ( $\mathrm{n}=8 \mathrm{CIE} / \mathrm{WD}+$ saline, $\mathrm{n}=7 \mathrm{CIE} / \mathrm{WD}+\mathrm{CNO})$ but not air-exposed controls ( $n=7$ Air+saline, $n=6$ Air+CNO). There was a significant main effect of CNO ( $<<0.05$, two-way ANOVA) with a significant increase in open arm time in the CIE/WD+CNO group compared to the CIE/WD+saline group $(*-p<0.05$, Bonferroni's multiple comparison test). As a proxy for locomotor behavior, there was no significant effect of CNO on 
closed arm entries in either treatment group $\left(\mathrm{B}_{2}\right)$. (C) Systemic CNO modulation of anxiety-like behavior requires expression of the hM4-Gi-DREADD in the cPO. In animals expressing only Channelrhodopsin in the cPO (“No DREADD” Controls), there was no significant effect of CNO systemic injection on either open arm time $\left(\mathrm{C}_{1}\right)$ or closed arm entries $\left(\mathrm{C}_{2}\right)$. However, CIE/WD animals ( $n=4, C I E / W D+$ saline, $n=4, C I E / W D+C N O)$ spent significantly less time in the open arms compared to Air-exposed controls (n=5, Air+saline, n=4 Air+CNO; main effect of CIE/WD, $\mathrm{p}<0.05$, two-way ANOVA).

Figure 4. Activation of $h M 4-G i-D R E A D D$ receptors expressed $c P O$ terminals in the lateral amygdala attenuates withdrawal-dependent anxiety-like behavior on the elevated plus maze. (A) Illustration of the approximate placement of guide cannulae (open circles) used in this analysis. Coronal brain slices have been modified from Paxinos and Watson (Paxinos and Watson, 2005). (B) Representative heat maps from the four treatment groups. (C) Microinjection of CNO into the lateral amygdala decreases anxiety-like behavior in CIE/WD animals but not air controls. There was a significant interaction between treatments (Air vs. CIE/WD and vehicle vs. CNO, two-way ANOVA) and a significant increase in open arm time in CIE/WD animals microinjected with CNO (*, $\mathrm{p}<0.05$, Bonferonni's multiple comparison post-test). There was a significant main effect of CIE/WD on total arm entries (C2) but no effect of CNO microinjection. (D) Modulation of withdrawal-associated anxiety-like behavior by CNO microinjection requires cPO expression of the hM4-Gi-DREADD. For the air-treated control groups $\left(\mathrm{D}_{1}\right)$, there was no significant difference between vehicle microinjection in Gi-DREADD animals, CNO microinjection in Gi-DREADD animals (data from Fig. 4C), and CNO microinjection in animals expressing only Channelrhodopsin ("No DREAD” controls, n=4; $\mathrm{p}>0.05$, on-way ANOVA). In the CIE/WD groups $\left(\mathrm{D}_{2}\right)$, attenuation of anxiety-like behavior 
required both Gi-DREADD expression in $\mathrm{cPO}$ terminals and $\mathrm{CNO}$ microinjection into the lateral amgydala ( $<<0.05$, one-way ANOVA; $\$$ - $\mathrm{p}<0.05$ relative to vehicle injected animals, \#\# $\mathrm{p}<0.01$ relative to “No DREADD” controls, $\mathrm{n}=5$, Bonferroni’s multiple comparison test). 


\section{References}

BORDI, F. \& LEDOUX, J. E. 1994a. Response properties of single units in areas of rat auditory thalamus that project to the amygdala. I. Acoustic discharge patterns and frequency receptive fields. Exp Brain Res, 98, 261-74.

BORDI, F. \& LEDOUX, J. E. 1994b. Response properties of single units in areas of rat auditory thalamus that project to the amygdala. II. Cells receiving convergent auditory and somatosensory inputs and cells antidromically activated by amygdala stimulation. Exp Brain Res, 98, 275-86.

CHO, J. H., BAYAZITOV, I. T., MELONI, E. G., MYERS, K. M., CARLEZON, W. A., JR., ZAKHARENKO, S. S. \& BOLSHAKOV, V. Y. 2012. Coactivation of thalamic and cortical pathways induces input timing-dependent plasticity in amygdala. Nat Neurosci, $15,113-22$.

CHRISTIAN, D. T., ALEXANDER, N. J., DIAZ, M. R. \& MCCOOL, B. A. 2013. Thalamic glutamatergic afferents into the rat basolateral amygdala exhibit increased presynaptic glutamate function following withdrawal from chronic intermittent ethanol. Neuropharmacology, 65, 134-142. 
CHRISTIAN, D. T., ALEXANDER, N. J., DIAZ, M. R., ROBINSON, S. \& MCCOOL, B. A. 2012. Chronic intermittent ethanol and withdrawal differentially modulate basolateral amygdala AMPA-type glutamate receptor function and trafficking. Neuropharmacology, 62, 2429-38.

DIAZ, M. R., CHAPPELL, A. M., CHRISTIAN, D. T., ANDERSON, N. J. \& MCCOOL, B. A. 2011a. Dopamine D3-like receptors modulate anxiety-like behavior and regulate GABAergic transmission in the rat lateral/basolateral amygdala. Neuropsychopharmacology, 36, 1090-1103.

DIAZ, M. R., CHRISTIAN, D. T., ANDERSON, N. J. \& MCCOOL, B. A. 2011b. Chronic ethanol and withdrawal differentially modulate basolateral amygdala paracapsular and local GABAergic synapses. J Pharmacol Exp Ther, 337, 162-170.

DORON, N. N. \& LEDOUX, J. E. 1999. Organization of projections to the lateral amygdala from auditory and visual areas of the thalamus in the rat. J Comp Neurol, 412, 383-409.

DORON, N. N. \& LEDOUX, J. E. 2000. Cells in the posterior thalamus project to both amygdala and temporal cortex: a quantitative retrograde double-labeling study in the rat. J Comp Neurol, 425, 257-74.

DOYERE, V., SCHAFE, G. E., SIGURDSSON, T. \& LEDOUX, J. E. 2003. Long-term potentiation in freely moving rats reveals asymmetries in thalamic and cortical inputs to the lateral amygdala. Eur J Neurosci, 17, 2703-15. 
EORDEGH, G., NAGY, A., BERENYI, A. \& BENEDEK, G. 2005. Processing of spatial visual information along the pathway between the suprageniculate nucleus and the anterior ectosylvian cortex. Brain Res Bull., 67, 281-9.

GAURIAU, C. \& BERNARD, J. F. 2004. Posterior triangular thalamic neurons convey nociceptive messages to the secondary somatosensory and insular cortices in the rat. $J$ Neurosci., 24, 752-61.

GIOIA, D. A., ALEXANDER, N. J. \& MCCOOL, B. A. 2017. Ethanol mediated inhibition of synaptic vesicle recycling at amygdala glutamate synapses is dependent upon Munc13-2. Front Neurosci., 11, 424.

GIOIA, D. A. \& MCCOOL, B. A. 2017. Strain-dependent effects of acute alcohol on synaptic vesicle recycling and post-tetanic potentiation in medial glutamate inputs to the mouse basolateral amygdala. Alcohol Clin Exp Res., 41, 735-746.

GONZALEZ-HERNANDEZ, A., MARTINEZ-LORENZANA, G., ROJAS-PILONI, G., RODRIGUEZ-JIMENEZ, J., HERNANDEZ-LINARES, Y., VILLANUEVA, L. \& CONDES-LARA, M. 2013. Spinal LTP induced by sciatic nerve electrical stimulation enhances posterior triangular thalamic nociceptive responses. Neuroscience., 234, 12534.

GOUSSAKOV, I., CHARTOFF, E. H., TSVETKOV, E., GERETY, L. P., MELONI, E. G., CARLEZON, W. A., JR. \& BOLSHAKOV, V. Y. 2006. LTP in the lateral amygdala during cocaine withdrawal. Eur J Neurosci, 23, 239-50. 
HALVERSON, H. E., POREMBA, A. \& FREEMAN, J. H. 2008. Medial auditory thalamus inactivation prevents acquisition and retention of eyeblink conditioning. Learn Mem., 15, $532-8$.

HUMEAU, Y., SHABAN, H., BISSIERE, S. \& LUTHI, A. 2003. Presynaptic induction of heterosynaptic associative plasticity in the mammalian brain. Nature, 426, 841-5.

KIM, J., LEE, S., PARK, K., HONG, I., SONG, B., SON, G., PARK, H., KIM, W. R., PARK, E., CHOE, H. K., KIM, H., LEE, C., SUN, W., KIM, K., SHIN, K. S. \& CHOI, S. 2007. Amygdala depotentiation and fear extinction. Proc Natl Acad Sci U S A, 104, 20955-60.

KOOB, G. F. 2003. Alcoholism: allostasis and beyond. Alcohol Clin Exp Res, 27, 232-43.

KOOB, G. F. 2013. Theoretical frameworks and mechanistic aspects of alcohol addiction: alcohol addiction as a reward deficit disorder. Curr Top Behav Neurosci, 13, 3-30.

KWON, J. T., NAKAJIMA, R., KIM, H. S., JEONG, Y., AUGUSTINE, G. J. \& HAN, J. H. 2014. Optogenetic activation of presynaptic inputs in lateral amygdala forms associative fear memory. Learn Mem., 21, 627-33.

LACK, A. K., CHRISTIAN, D. T., DIAZ, M. R. \& MCCOOL, B. A. 2009. Chronic ethanol and withdrawal effects on kainate receptor-mediated excitatory neurotransmission in the rat basolateral amygdala. Alcohol, 43, 25-33. 
LACK, A. K., DIAZ, M. R., CHAPPELL, A., DUBOIS, D. W. \& MCCOOL, B. A. 2007. Chronic ethanol and withdrawal differentially modulate pre- and postsynaptic function at glutamatergic synapses in rat basolateral amygdala. J Neurophysiol, 98, 3185-96.

LANUZA, E., MONCHO-BOGANI, J. \& LEDOUX, J. E. 2008. Unconditioned stimulus pathways to the amygdala: effects of lesions of the posterior intralaminar thalamus on foot-shock-induced c-Fos expression in the subdivisions of the lateral amygdala. Neuroscience, 155, 959-68.

LEDOUX, J. E., FARB, C. \& RUGGIERO, D. A. 1990. Topographic organization of neurons in the acoustic thalamus that project to the amygdala. $J$ Neurosci, 10, 1043-54.

LEDOUX, J. E. \& FARB, C. R. 1991. Neurons of the acoustic thalamus that project to the amygdala contain glutamate. Neurosci Lett, 134, 145-9.

LINKE, R., BRAUNE, G. \& SCHWEGLER, H. 2000. Differential projection of the posterior paralaminar thalamic nuclei to the amygdaloid complex in the rat. Exp Brain Res., 134, 520-32.

LIPSHETZ, B., KHASABOV, S. G., TRUONG, H., NETOFF, T. I., SIMONE, D. A. \& GIESLER, G. J., JR. 2018. Responses of thalamic neurons to itch- and pain-producing stimuli in rats. J Neurophysiol., 120, 1119-1134.

MCCOOL, B. A. 2011. Ethanol modulation of synaptic plasticity. Neuropharmacology, 61, 1097-1108. 
MCCOOL, B. A. \& CHAPPELL, A. 2007. Strychnine and taurine modulation of amygdalaassociated anxiety-like behavior is 'state' dependent. Behav Brain Res, 178, 70-81.

MCCOOL, B. A., CHRISTIAN, D. T., DIAZ, M. R. \& LACK, A. K. 2010. Glutamate plasticity in the drunken amygdala: the making of an anxious synapse. Int Rev Neurobiol, 91, 20533.

MCCOOL, B. A., CHRISTIAN, D. T., FETZER, J. A. \& CHAPPELL, A. M. 2014. Lateral/basolateral amygdala serotonin type-2 receptors modulate operant selfadministration of a sweetened ethanol solution via inhibition of principal neuron activity. Front Integr Neurosci, 8, 5.

MCDONALD, A. J. 1982. Neurons of the lateral and basolateral amygdaloid nuclei: a Golgi study in the rat. J Comp Neurol, 212, 293-312.

MCDONALD, A. J. 1985. Immunohistochemical identification of gamma-aminobutyric acidcontaining neurons in the rat basolateral amygdala. Neurosci Lett, 53, 203-7.

MCDONALD, A. J. 1992. Projection neurons of the basolateral amygdala: a correlative Golgi and retrograde tract tracing study. Brain Res Bull, 28, 179-85.

MORALES, M., MCGINNIS, M. M. \& MCCOOL, B. A. 2015. Chronic ethanol exposure increases voluntary home cage intake in adult male, but not female, Long-Evans rats. Pharmacol Biochem Behav., 139, 67-76. 
MORALES, M., MCGINNIS, M. M., ROBINSON, S. L., CHAPPELL, A. M. \& MCCOOL, B.

A. 2018. Chronic intermittent ethanol exposure modulation of glutamatergic neurotransmission in rat lateral/basolateral amygdala is duration-, input-, and sexdependent. Neuroscience, 371, 277-287.

NASSER, H. M. \& MCNALLY, G. P. 2013. Neural correlates of appetitive-aversive interactions in Pavlovian fear conditioning. Learn Mem., 20, 220-8.

NITECKA, L., AMERSKI, L., PANEK-MIKULA, J. \& NARKIEWICZ, O. 1979. Thalamoamygdaloid connections studied by the method of retrograde transport. Acta Neurobiol Exp (Wars), 39, 585-601.

PARK, S., LEE, J., PARK, K., KIM, J., SONG, B., HONG, I., KIM, J., LEE, S. \& CHOI, S. 2016. Sound tuning of amygdala plasticity in auditory fear conditioning. Sci Rep., 6, 31069.

PAXINOS, G. \& WATSON, C. 2005. The rat brain in stereotaxic coordinates -- the new coronal set, Burlington MA, Elsevier Academic Press.

RAINNIE, D. G., ASPRODINI, E. K. \& SHINNICK-GALLAGHER, P. 1993. Intracellular recordings from morphologically identified neurons of the basolateral amygdala. $J$ Neurophysiol, 69, 1350-62.

RICH, M. T., HUANG, Y. H. \& TORREGROSSA, M. M. 2019. Plasticity at Thalamo-amygdala Synapses Regulates Cocaine-Cue Memory Formation and Extinction. Cell Rep., 26, 1010-1020. 
ROBINSON, S. L., ALEXANDER, N. J., BLUETT, R. J., PATEL, S. \& MCCOOL, B. A. 2016. Acute and chronic ethanol exposure differentially regulate CB1 receptor function at glutamatergic synapses in the rat basolateral amygdala. Neuropharmacology., 108, 474-

84.

ROBINSON, S. L. \& MCCOOL, B. A. 2015. Microstructural analysis of rat ethanol and water drinking patterns using a modified operant self-administration model. Physiol Behav., 149, 119-30.

ROMANSKI, L. M. \& LEDOUX, J. E. 1992. Equipotentiality of thalamo-amygdala and thalamo-cortico-amygdala circuits in auditory fear conditioning. J Neurosci, 12, 4501-9.

SHIN, R. M., TULLY, K., LI, Y., CHO, J. H., HIGUCHI, M., SUHARA, T. \& BOLSHAKOV, V. Y. 2010. Hierarchical order of coexisting pre- and postsynaptic forms of long-term potentiation at synapses in amygdala. Proc Natl Acad Sci U S A, 107, 19073-8.

SHINNICK-GALLAGHER, P., MCKERNAN, M. G., XIE, J. \& ZINEBI, F. 2003. L-type voltage-gated calcium channels are involved in the in vivo and in vitro expression of fear conditioning. Ann N Y Acad Sci, 985, 135-49.

SIUDA, E. R., AL-HASANI, R., MCCALL, J. G., BHATTI, D. L. \& BRUCHAS, M. R. 2016. Chemogenetic and Optogenetic Activation of Galphas Signaling in the Basolateral Amygdala Induces Acute and Social Anxiety-Like States. Neuropsychopharmacology, 41, 2011-23. 
SMITH, P. H., UHLRICH, D. J. \& MANNING, K. A. 2019. Evaluation of medial division of the medial geniculate (MGM) and posterior intralaminar nucleus (PIN) inputs to the rat auditory cortex, amygdala, and striatum. J Comp Neurol, 28, 1-17.

THOMAS, K. L. \& EVERITT, B. J. 2001. Limbic-cortical-ventral striatal activation during retrieval of a discrete cocaine-associated stimulus: a cellular imaging study with gamma protein kinase C expression. J Neurosci., 21, 2526-35.

TYE, K. M., STUBER, G. D., DE RIDDER, B., BONCI, A. \& JANAK, P. H. 2008. Rapid strengthening of thalamo-amygdala synapses mediates cue-reward learning. Nature, 453, 1253-7.

VAN KERKHOF, L. W., TREZZA, V., MULDER, T., GAO, P., VOORN, P. \& VANDERSCHUREN, L. J. 2014. Cellular activation in limbic brain systems during social play behaviour in rats. Brain Struct Funct., 219, 1181-211.

WASHBURN, M. S. \& MOISES, H. C. 1992. Electrophysiological and morphological properties of rat basolateral amygdaloid neurons in vitro. J Neurosci, 12, 4066-79. 
Figure 1

$A_{1}$

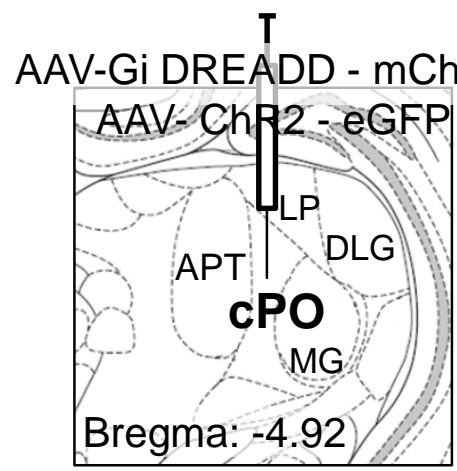

$B_{1}$

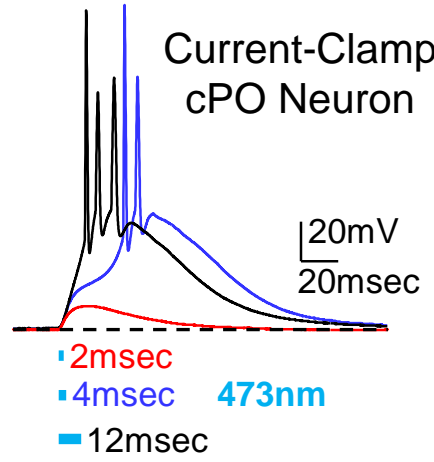

$B_{2}$

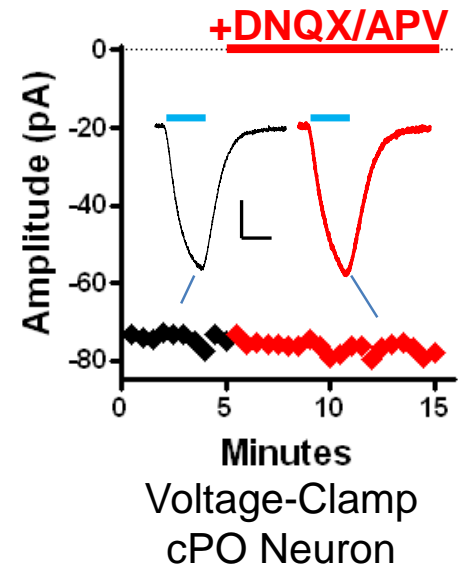

$A_{2}$
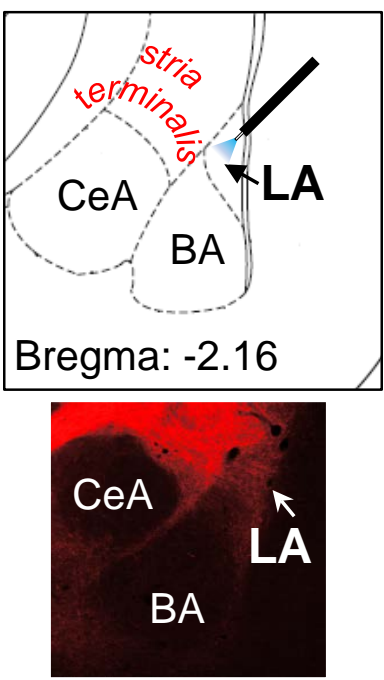

$\mathrm{C}_{1}$

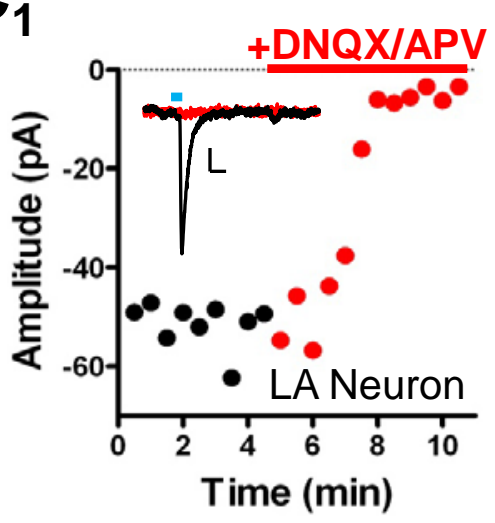

$\mathrm{C}_{2}$

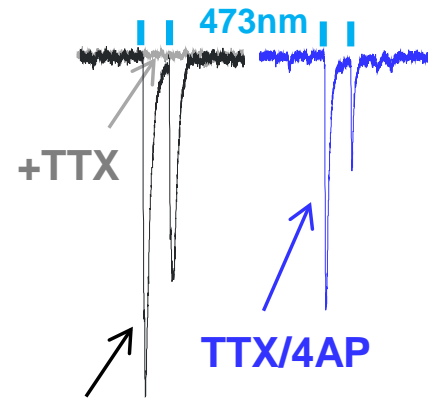

Baseline

LA Neuron 
$A_{1}$

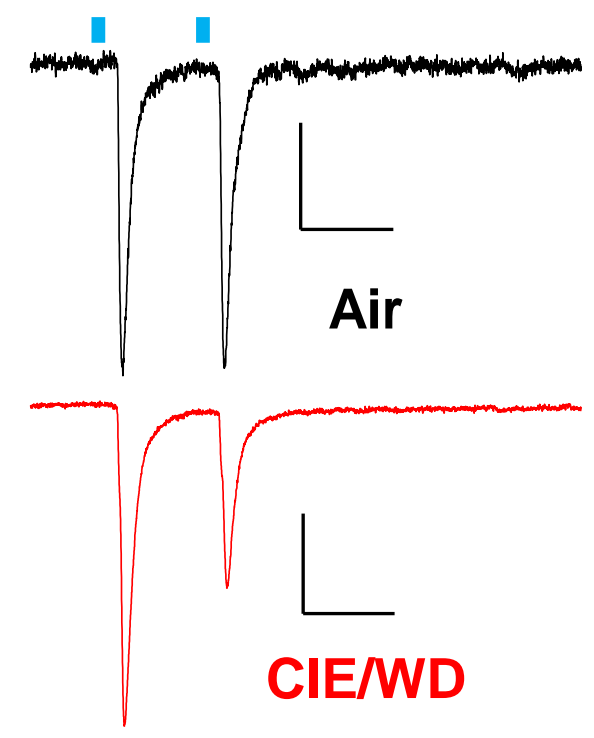

$B_{1}$

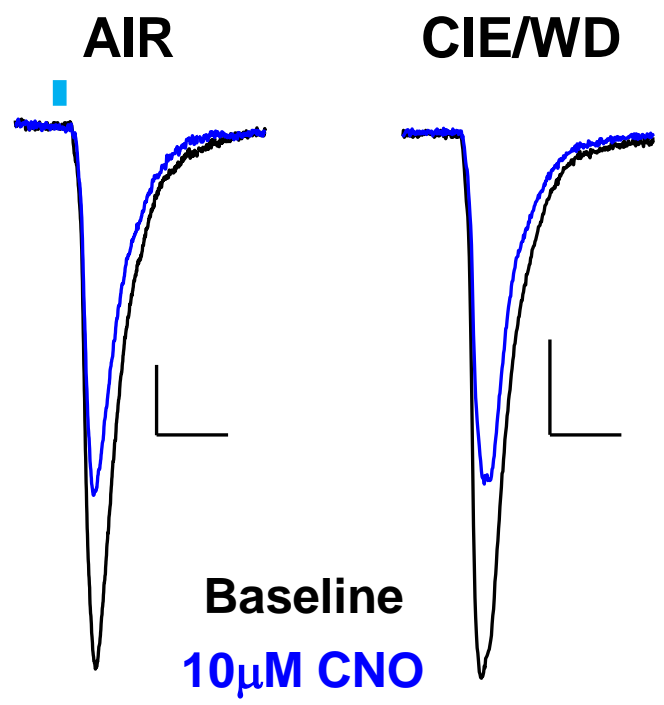

$\mathrm{A}_{2}$ cPO Paired Pulse

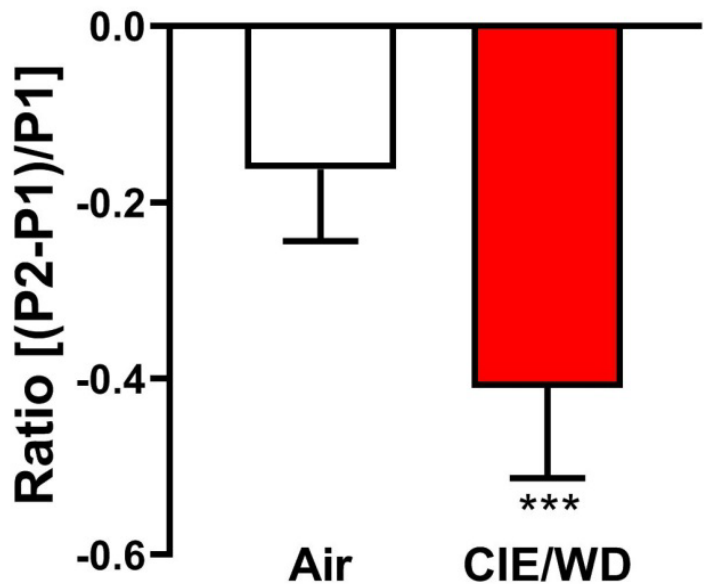

Exposure

$\mathrm{B}_{2}$

CNO $(10 \mu \mathrm{M})$

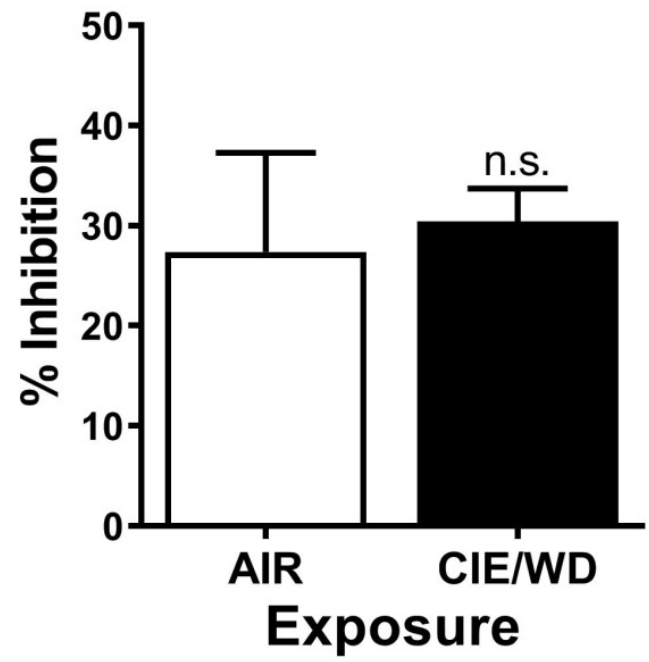


Figure 3

Systemic Injections

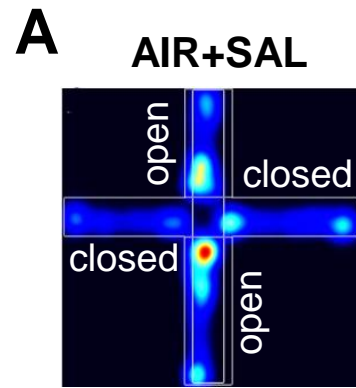

AIR+CNO

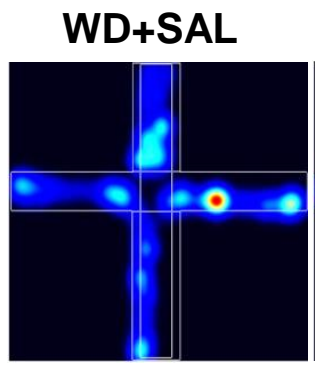

WD+CNO
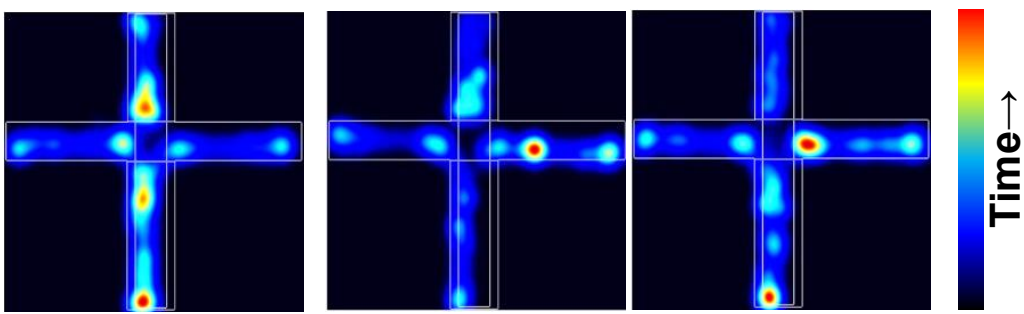

Gi-DREADD in cPO

$\mathrm{B}_{1}$

Open Arm Time

$\mathrm{B}_{2}$ Total Arm Entries
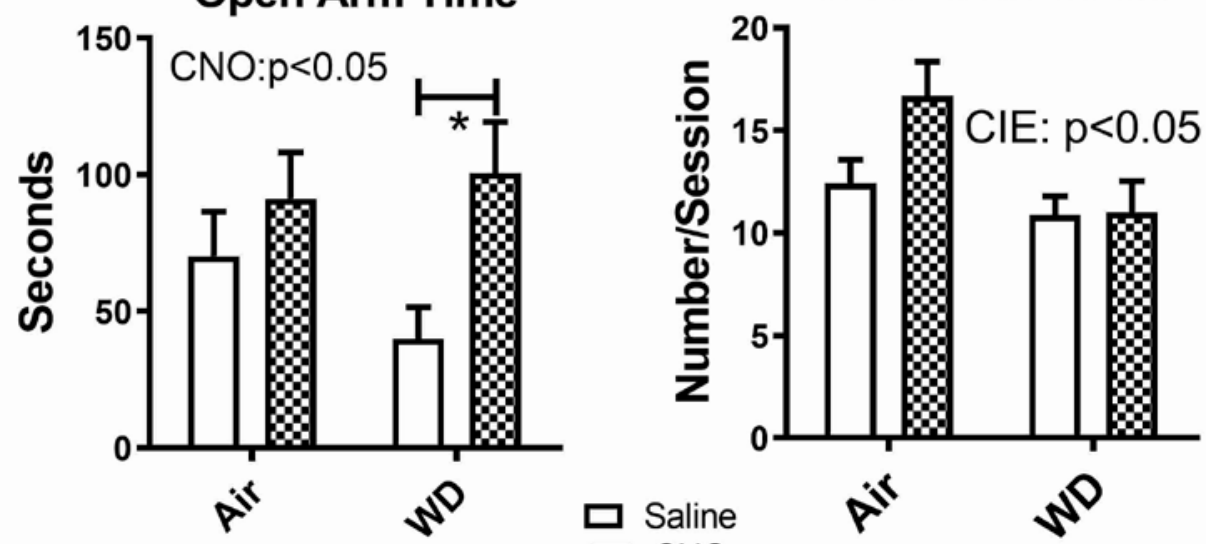

口 Saline

“No DREADD" Controls

$C_{1}$

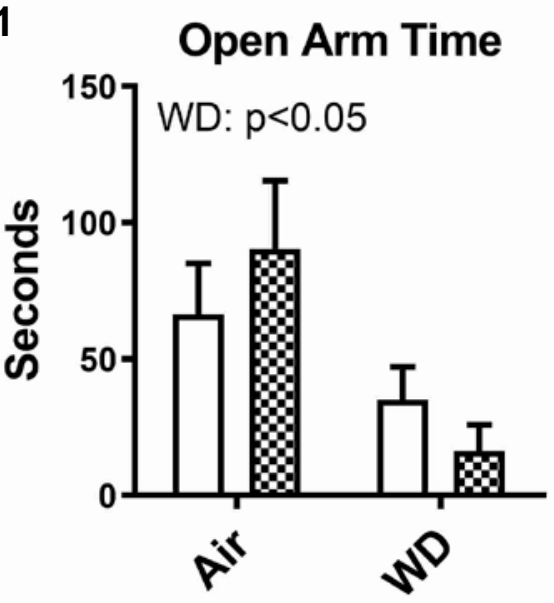

$\mathrm{C}_{2}$

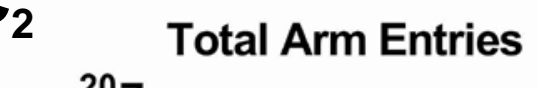

Saline

b $\mathrm{CNO}$

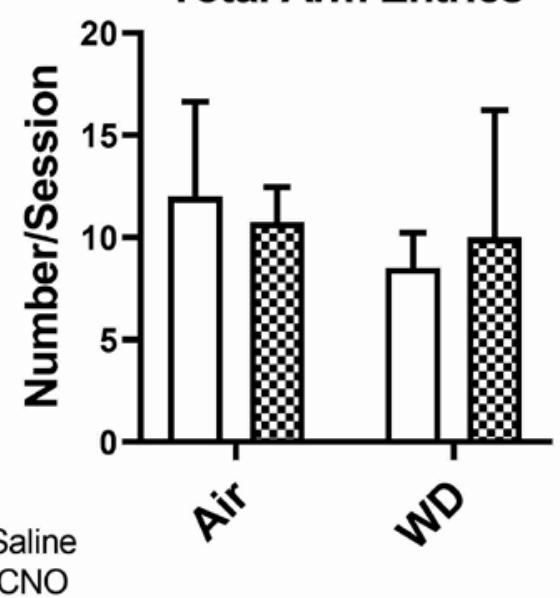



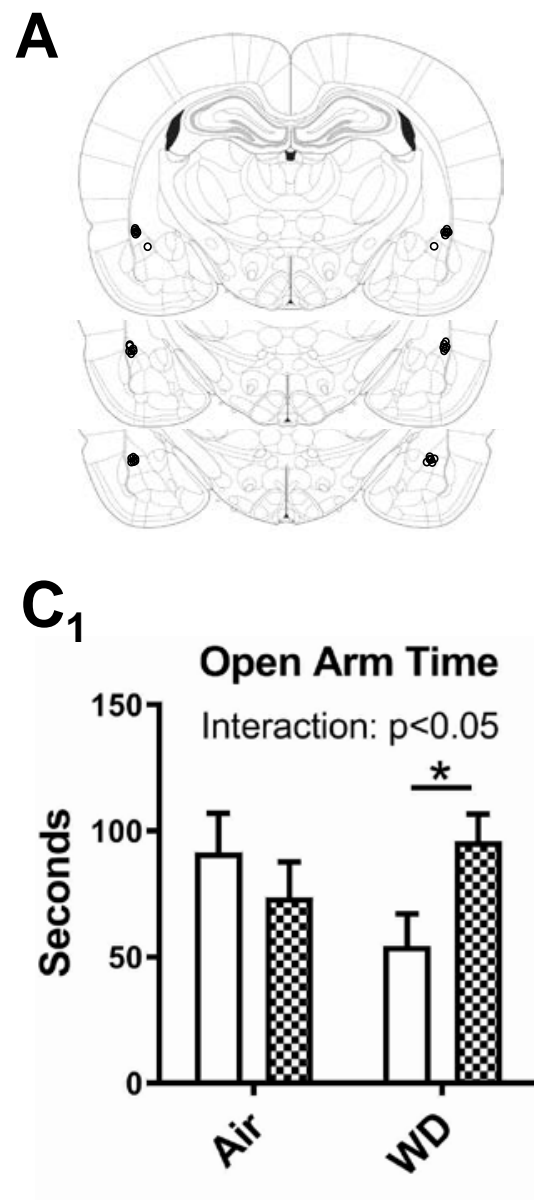

$D_{1}$

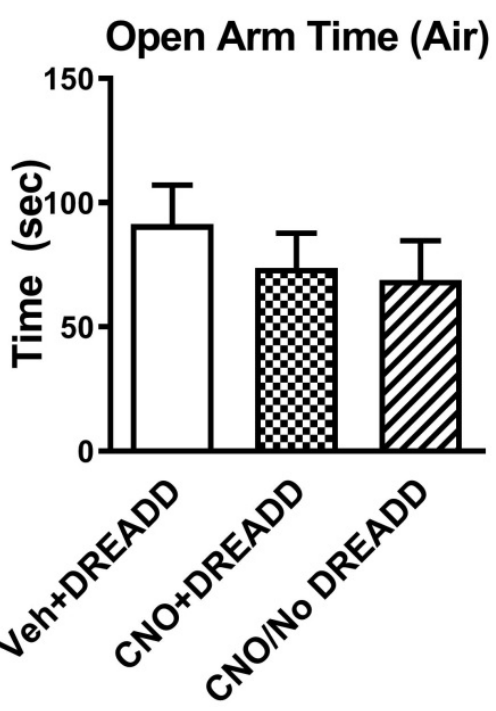

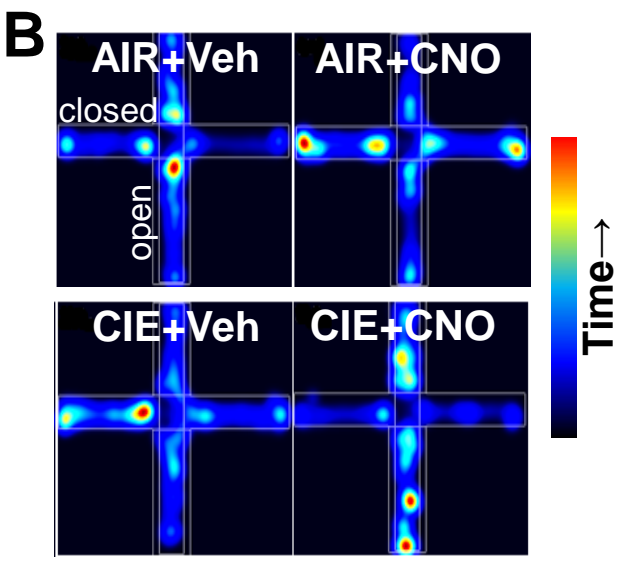

$\mathrm{C}_{2}$

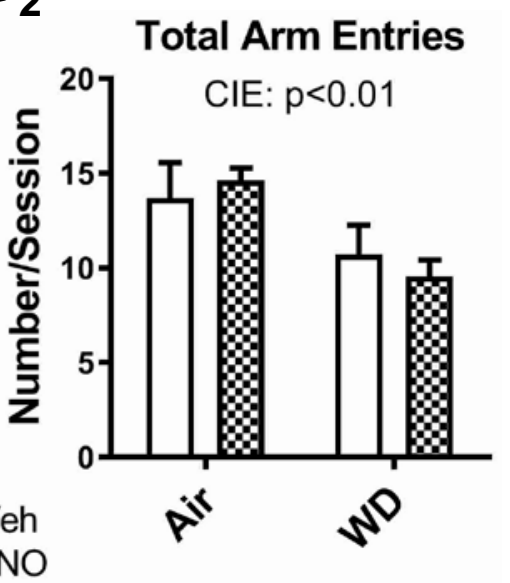

$D_{2}$

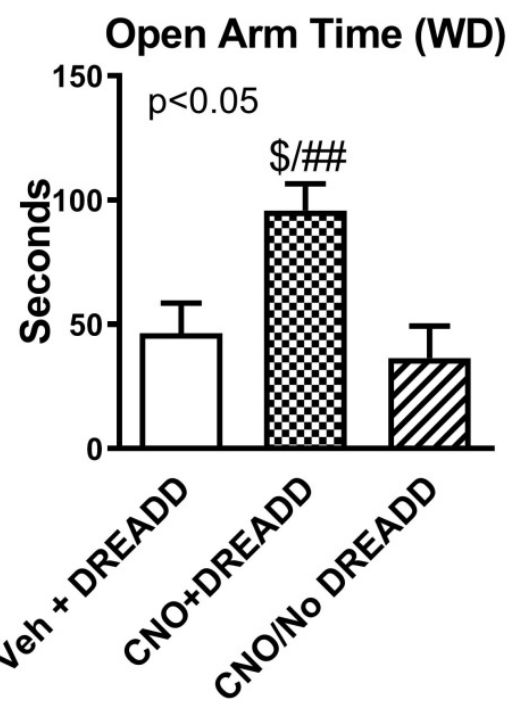

